\title{
Alterações no perfil dos lábios de pacientes submetidos a avanços maxilares em cirurgia ortognática do tipo Le Fort I*
}

\author{
Luciano Mauro DEL SANTO**, Ricardo Pires de SOUZA***, Marinho DEL SANTO JR.****,

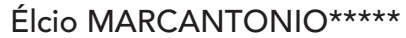

\begin{abstract}
Resumo
A literatura que descreve os resultados das correções cirúrgicas nos tecidos moles é limitada, pois apresenta significativa variação e não oferece conclusões definitivas. O propósito desse artigo é estudar retrospectivamente os efeitos das cirurgias ortognáticas maxilares tipo Le Fort I nos lábios superiores e inferiores de pacientes adultos e discutir os potenciais problemas envolvidos com a metodologia aplicada. Foram estudados 19 pacientes brancos de 19 a 42 anos de idade, sendo 10 homens e 9 mulheres, submetidos a cirurgias maxilares no Centro de Pesquisa e Tratamento das Deformidades Buco-Faciais - CEDEFACE (Araraquara, SP). A grande maioria dos casos apresentou, no mínimo, uma discrepância significativa, seja ântero-posterior ou vertical, reforçando a sua indicação cirúrgica. As alterações nos tecidos moles foram significativas quando as movimentações horizontais ou verticais da base óssea maxilar foram significativas, com uma relação de aproximadamente 0,6:1 entre as alterações ânteroposteriores do lábio superior e a movimentação da base óssea. Alterações verticais na maxila, sem significativas alterações horizontais, não foram suficientes para aumentar verticalmente o lábio superior. Ocorreram alterações ântero-posteriores do lábio inferior em conseqüência do deslocamento anterior e inferior da maxila, o que permitiu um melhor selamento labial. Alterações verticais não foram quantificadas no lábio inferior.
\end{abstract}

Palavras-chave: Cirurgia maxilar. Osteotomia Le Fort I. Perfil facial. Perfil labial.

\section{INTRODUÇÃO E REVISÃO DE LITERATURA}

Artigos que descrevam a influência de correções cirúrgicas de más oclusões nos tecidos moles são raros e limitados $12,23,24,26,32$. Isso porque as osteotomias maxilares anteriores ${ }^{14}$, posteriores $^{36} \mathrm{e}$ totais $^{38}$ só se tornaram mais populares na década de 1960, quando os trabalhos de Bell ${ }^{4,5,6}$ descreveram as bases biológicas da irrigação maxilar e

\footnotetext{
* Resumo da Dissertação de Mestrado apresentada ao Curso de Pós-Graduação em Ciências da Saúde do Hospital Heliópolis (HospHel) - São Paulo

** Cirurgião Bucomaxilofacial. Mestrado em Cirurgia Bucomaxilofacial no Curso de Pós-Graduação em Ciências da Saúde do Hospital Heliópolis (HospHel) / São Paulo. Residência em Cirurgia e Traumatologia Bucomaxilofacial da Faculdade de Odontologia UNESP/Araraquara. Especialista em Cirurgia Bucomaxilofacial pelo Colégio Brasileiro de Cirurgia e Traumatologia Bucomaxilofacial.

*** Orientador e Professor do Curso de Pós-Graduação em Ciências da Saúde do Hospital Heliópolis (HospHel) - São Paulo.

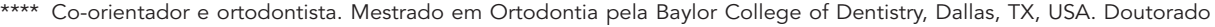
em Anatomia pelo Instituto de Ciências Biomédicas, USP/São Paulo.

**** Professor Titular do Departamento de Cirurgia e Traumatologia Bucomaxilofacial das Faculdades de Odontologia UNESP/Araraquara e UNAERP/Ribeirão Preto. Presidente do Centro de Pesquisa e Tratamento das Deformidades Buco-Faciais - CEDEFACE (Araraquara, SP).
} 
confirmaram as técnicas já empiricamente utilizadas. A partir desses trabalhos, os cirurgiões passaram a propor com maior freqüência osteotomias para a correção de deformidades maxilares em pacientes adultos. Os efeitos de tais procedimentos nos tecidos moles, como conseqüência das alterações dos tecidos duros, passaram a ser amplamente estudados porque os profissionais devem esclarecer aos pacientes as limitações das técnicas propostas.

Bell e Dann ${ }^{7}$ examinaram as mudanças que ocorreram nos tecidos moles de 25 pacientes que sofreram avanços e segmentações maxilares. Tais pacientes apresentavam mordidas abertas, protrusões bimaxilares ou Classe II esqueletais. Radiografias pós-cirúrgicas foram tomadas com um mínimo de 6 meses após a cirurgia. Procedimentos mentonianos (genioplastia) foram realizados em 11 pacientes, sendo que 8 sofreram avanço do mento e 3 foram submetidos a implantes de silicone. Os autores descreveram coeficiente de correlação entre as mudanças horizontais na posição do lábio superior (vermelhão do lábio) e a ponta do incisivo central superior igual a 0,73 . Os autores sugeriram a proporção de 0,7 $\pm 0,1 \mathrm{~mm}$ para predicção da posição do lábio superior após procedimentos cirúrgicos maxilares anteriores. Além disso, os autores mencionaram que as mudanças nos tecidos moles acompanham as mudanças dos tecidos duros e existe boa previsibilidade das alterações dos tecidos moles relativa às alterações dos tecidos duros. A proporção do movimento do lábio superior à borda incisal é uma explicação simplificada do movimento na direção ântero-posterior. Na verdade, o que ocorre é uma combinação de movimentos horizontais e verticais. Os movimentos verticais também ocorrem com a movimentação da maxila, mas não são facilmente mensurados. As mudanças observadas no sulco naso-labial são mínimas e a espessura dos lábios certamente influenciou nos resultados. As mudanças observadas se tornam mais aparentes no vermelhão do lábio, pois há a eversão do lábio, porém, tais mudanças não foram confirmadas estatisticamente.
Radney e Jacobs ${ }^{31}$ examinaram os efeitos da intrusão total da maxila (com osteotomias Le Fort I) em 10 adultos que apresentavam excesso vertical maxilar ou "síndrome da face longa". A amostra era constituída de 9 mulheres e 1 homem, entre 16 a 52 anos, todos caucasianos e sem significativas alterações de crescimento. Para os autores, é de fundamental importância que o ortodontista e o cirurgião prevejam as mudanças a serem esperadas de um procedimento cirúrgico. A resposta dos tecidos moles à movimentação dos tecidos duros foi estudada através da comparação de radiografias laterais pré e pós-operatórias. Os autores constataram que as respostas do ângulo naso-labial variam de acordo com a direção e a quantidade de intrusão maxilar. Quando a maxila foi impactada e retruída, o ângulo naso-labial geralmente aumentou. Entretanto, poucas mudanças aconteceram no ângulo naso-labial quando a maxila foi intruída e protruída ou somente intruída.

Nos pacientes em que a maxila foi impactada e retruída, o ponto mais anterior do lábio superior respondeu ao movimento do incisivo superior na proporção de 0,7:1. A ponta do nariz se moveu ligeiramente para cima com a intrusão e protrusão maxilar. A cada $6 \mathrm{~mm}$ de movimentação maxilar, a ponta do nariz se moveu $1 \mathrm{~mm}$ para cima. Nos casos em que a maxila foi impactada e protruída, o lábio superior respondeu ao incisivo superior na proporção 0,5:1. A proporção do movimento do sulco superior labial e sub-nasal em relação ao incisivo central foi de 0,3:1. Isso significa que os tecidos moles do lábio superior avançaram praticamente a metade do que os incisivos superiores avançaram. A borda inferior do lábio superior se moveu para cima com a intrusão da maxila. A proporção encontrada foi de 0,4:1.

As mudanças nos lábios inferiores foram imprevisíveis, possivelmente devido às diferenças no tônus muscular dos tecidos moles na época em que a radiografia foi tomada. $\mathrm{O}$ mento mole respondeu à intrusão maxilar com uma rotação, acompanhando as mudanças observadas no mento ósseo, na proporção de 1:1. 
Mansour et al. ${ }^{26}$ estudaram as respostas dos tecidos moles de 21 pacientes adultos que sofreram cirurgia maxilar com osteotomia Le Fort I e que não sofreram nenhuma intervenção mandibular. Os autores examinaram as radiografias laterais de 14 pacientes que haviam sofrido impacções maxilares e 7 pacientes que haviam sofrido avanços maxilares. Os autores escolheram 3 pontos cefalométricos para calcular a correlação entre as alterações dos tecidos moles e os tecidos duros, usando análise de regressão múltipla. Os desvios padrão das correlações foram significativamente altos se a amostra fosse considerada como um todo. Por isso, os autores decidiram analisar os dados dos grupos específcos. Os autores categorizaram as cirurgias maxilares em impacções e avanços, embora essa divisão seja até certo ponto arbitrária, uma vez que a maioria das impacções envolve também algum avanço ou retrocesso. Por isso, os casos foram divididos primariamente em casos que sofreram mudanças maiores e casos que sofreram mudanças menores.

Segundo esses autores, as reações observadas nos tecidos moles parecem ser previsíveis, embora a precisão seja limitada. As proporções obtidas foram estatisticamente significativas, mas deve-se notar o grande desvio padrão envolvido, o que não significa que os resultados não sejam clinicamente aceitáveis, mas sim que o clínico deve ter em mente que a variação individual é expressiva.

$\mathrm{Na}$ impacção, o lábio superior seguiu os movimentos dos incisivos superiores no plano horizontal, os tecidos moles mandibulares seguiram a auto-rotação esqueletal mandibular na proporção de 1:1 e a borda inferior do lábio superior se moveu superiormente aproximadamente $40 \%$ da alteração vertical maxilar. No avanço, houve um aumento progressivo no movimento horizontal do tecido mole, da ponta do nariz à ponta do lábio superior e as mudanças verticais e horizontais do tecido mole mandibular foram imprevisíveis. A proporção entre o movimento vertical do lábio superior e a borda incisal do incisivo superior foi de 0,4:1.É importante salientar que as alterações verticais do lábio inferior em relação aos incisivos inferiores chega a ser de 0,9:1. Outros fatores envolvidos nessa proporção não são ainda devidamente elucidados e uma previsão acurada do resultado final continua sendo inatingível. Os coeficientes de correlação entre os três pontos cefalométricos utilizados indicaram que o ponto mais proeminente do lábio superior foi o mais previsivel em termos de alterações horizontais e o Prostion foi o mais previsível das alterações verticais. Houve um movimento substancial na ponta do nariz (Pronasale) e no plano da base do lábio superior, entretanto, não houve uma significativa correlação nas mudanças horizontais desses dois pontos cefalométricos. $\mathrm{O}$ Labrale Superius respondeu seguindo o movimento da superfície labial do incisivo maxilar no plano horizontal. No plano vertical, os autores encontraram uma proporção de $0,4: 1$ no movimento do Stomion Superius em relação à borda incisal. Quanto maior a área do lábio, menos mudanças horizontais foram observadas. Assim, os autores sugerem que a espessura do lábio superior deve ser cuidadosamente avaliada antes dos resultados predictivos serem apresentados aos pacientes.

Embora muitos trabalhos relacionem os efeitos das mudanças ósseas nos tecidos moles e coeficientes de correlações dessas mudanças 1 1,3,5, $7,8,12,13,17,18,19,20,21,23,24,25,26,31,32,35,37$, todos apresentam significativa variação e não oferecem resultados definitivos.

\section{PROPOSIÇÃO}

O propósito desse artigo é estudar retrospectivamente os efeitos em adultos dos avanços maxilares em cirurgia ortognática do tipo Le Fort I tendo os seguintes objetivos:

- Avaliar as alterações verticais e horizontais nos lábios superiores

- Avaliar as conseqüentes alterações em lábios inferiores.

\section{MATERIAIS E MÉTODOS Amostra}

A amostra foi formada por 19 pacientes brancos 
de 19 a 42 anos de idade, sendo 10 homens e 9 mulheres. Todos os pacientes foram submetidos a cirurgias maxilares com osteotomias Le Fort I e não foram submetidos a nenhum procedimento cirúrgico mandibular. Pacientes com má formação congênita, sindrômicos ou que haviam sido submetidos a qualquer outro procedimento ortognático-cirúrgico anteriormente não foram incluídos na amostra.

Todos os pacientes foram operados no Centro de Pesquisa e Tratamento das Deformidades Buco-Faciais - CEDEFACE (Araraquara/SP), por cirurgiões e residentes da Disciplina de Cirurgia e Traumatologia Bucomaxilofacial da Faculdade de Odontologia de Araraquara - FOAr/UNESP. O planejamento cirúrgico incluiu análise facial, traçado cefalométrico e montagem de modelos em articulador semi-ajustável.

\section{Documentações ortodôntico-cirúrgicas}

Documentações ortodôntico-cirúrgicas, incluindo fotografias extra e intra-orais, ortopantomografias (radiografias panorâmicas), radiografias laterais e modelos de gesso foram executados para todos os pacientes. As documentações iniciais (Tl) foram feitas antes do início do tratamento ortodôntico-cirúrgico e as finais pelo menos 1 ano após a cirurgia (T2). Todas radiografias laterais foram tomadas no mesmo aparelho de Raio X, pertencente à FOAr/ UNESP. Em todas radiografias os pacientes foram orientados para manterem seus lábios em posição de repouso durante a tomada radiográfica.

\section{Pontos cefalométricos e variáveis}

Em cada radiografia lateral (T1 e T2), os seguintes pontos cefalométricos foram identificados (Fig. 1) 27 :

1) Sela: centro da concavidade óssea da sela túrcica;

2) Násio: intersecção da sutura internasal com a sutura frontonasal;

3) Básio: ponto mais póstero-inferior da porção anterior do forame magno;

4) Pório: ponto mais superior do meato audi- tivo externo;

5) Orbitário: ponto mais inferior da margem orbitária;

6) Ponto A: ponto mais profundo da concavidade anterior da maxila;

7) Incisal do incisivo superior: ponto mais inferior da coroa do incisivo superior;

8) Ápice do incisivo superior: ponto mais superior da raiz do incisivo central superior;

9) Média das cúspides dos pré-molares superiores;

10) Ponto B: ponto mais profundo da concavidade anterior da mandíbula;

11) Gnátio: ponto mais ântero-inferior do contorno do mento ósseo;

12) Ponta do nariz: ponto mais anterior do nariz;

13) Ponto naso-labial: intersecção entre a base inferior do nariz e ponto mais superior do lábio superior;

14) Lábio superior: ponto mais anterior do lábio superior, na borda mais superior do vermelhão do lábio;

15) Lábio inferior: ponto mais anterior do lábio inferior, na borda mais inferior do vermelhão do lábio;

16) Estômio: união do lábio superior com o lábio inferior;

17) Pogônio mole: ponto mais anterior do tecido mole do mento.

Os seguintes planos foram identificados (Fig. 2):

1) Base craniana: do ponto Sela ao ponto Násio.

2) Frankfurt: do ponto Pório ao ponto Orbitário.

3) Oclusal: plano formado pela interseção das cúspides dos pré-molares superiores e inferiores e interseção dos incisivos centrais superiores e inferiores.

E as seguintes variáveis definidas (Fig. 2, 3).

1) SNA: ângulo formado pelos pontos Sela 


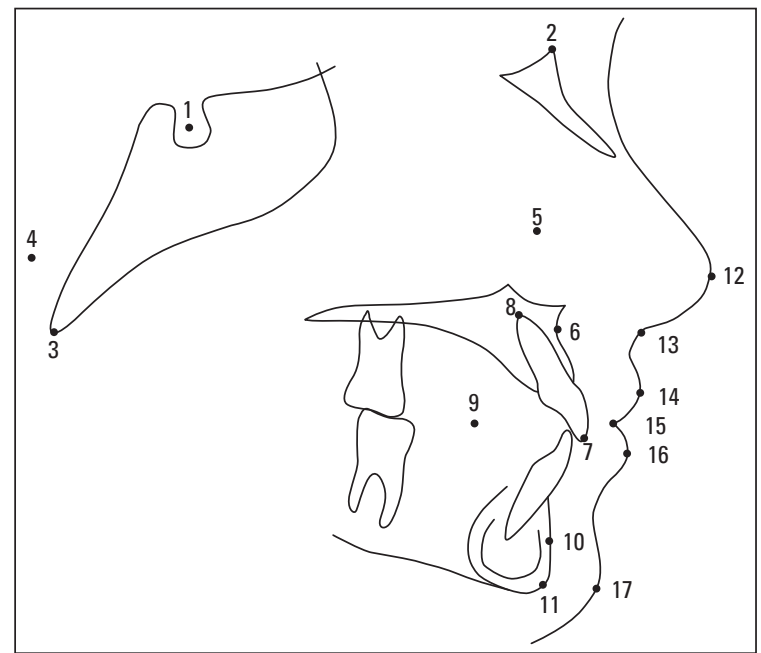

Figura 1

(ponto 1), Násio (ponto 2) e Ponto A (ponto 6).

2) INCNA: ângulo formado pelo longo eixo dos incisivos superiores (pontos 7 e 8) e linha NA (pontos 2 a 6).

3) SNPO: ângulo formado pela linha Sela-Násio (pontos 1 e 2) e plano oclusal (pontos 7 a 9).

4) ANVERT: distância do Ponto A à perpendicular ao plano de Frankfurt (pontos 4 e 5), passando por Násio (ponto 2).

5) NASO (ângulo naso-labial): formado pela linha que tangencia a base inferior do nariz e linha que tangencia o contorno mais superior do lábio

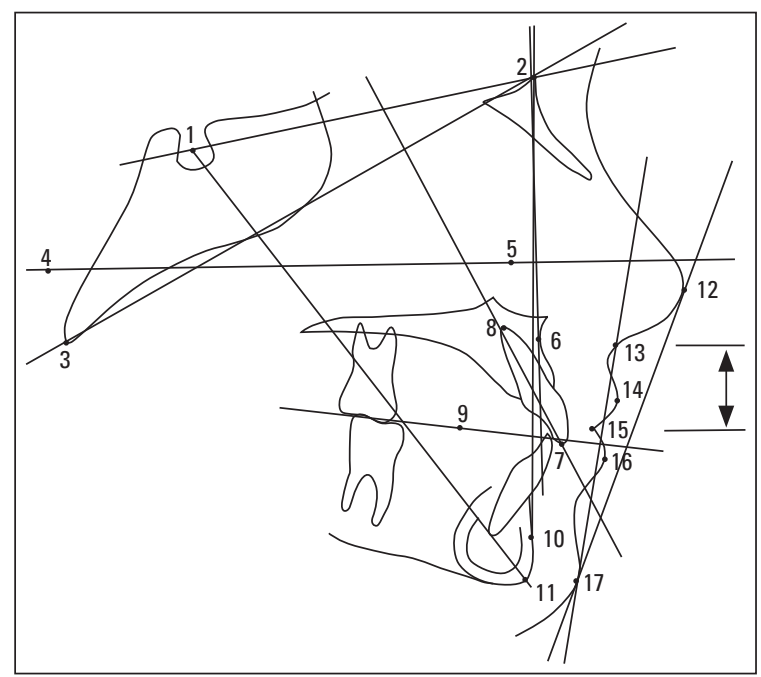

Figura 2 superior, unidas no ponto 13 .

6) EIXOY: interseção das linhas Násio-Básio (pontos 2 a 3) e Sela-Gnátio (pontos 1 e 2).

7) LSEST: distância do lábio superior (14) à linha estética (pontos 12 a 17, linha que une o ponto mais anterior do nariz ao ponto mais anterior do mento).

8) LSBUR: distância do lábio superior (14) à linha de Burstone (pontos 13 a 17, linha que une o ponto naso-labial ao ponto mais anterior do mento).

9) LIEST: distância do lábio inferior (16) à linha estética (pontos 12 a 17, linha que une o ponto mais anterior do nariz ao ponto mais anterior do mento).

10) LIBUR: distância do lábio inferior (16) à linha de Burstone (pontos 13 a 17, linha que une o ponto naso-labial ao ponto mais anterior do mento).

11) ALTLA (altura do lábio superior): distância entre o ponto naso-labial (ponto 13) e Estômio (ponto 15).

\section{Coleta de dados}

As radiografias laterais (T1 e T2) foram traçadas pelo autor, com lapiseira 0,03, em papel acetato específico para traçados ortodônticos. As radiografias foram digitalizadas em mesa digitalizadora

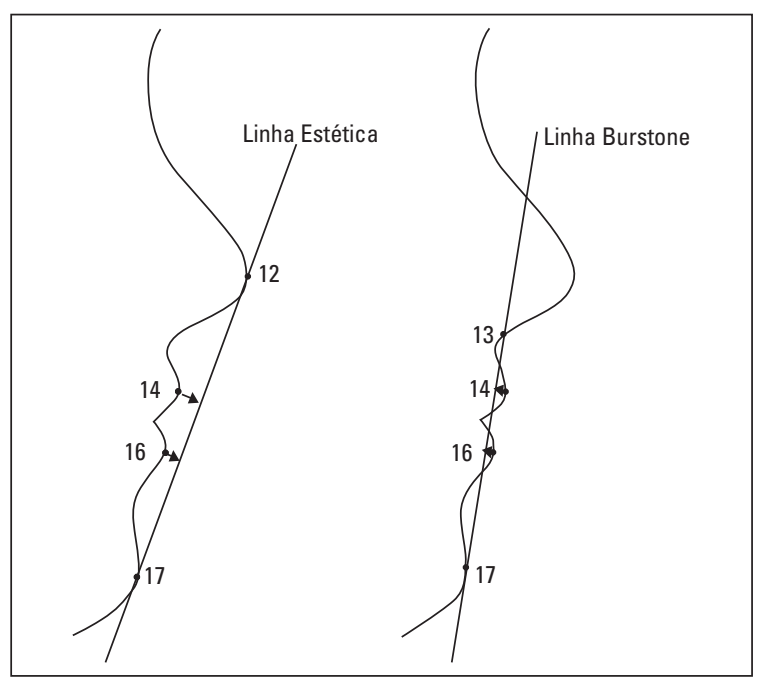

Figura 3 
e software DFPlus (DFPlus: Dentofacial Software Inc.,1995. 1 First Canadian Place, Suite 870 Toronto, Ontario, Canada, M5X 1C9.), gentilmente cedido pelo Departamento de Ortodontia da FOAr/UNESP.

\section{Grau de confiabilidade}

Uma sub-amostra de 5 pacientes (radiografias inicial e final) aleatoriamente escolhida foi re-traçada e re-digitalizada pelo mesmo pesquisador com o mesmo método, com um intervalo de uma semana, para se calcular a confiança intra-observador. O erro sistemático não foi estatisticamente significativo para nenhuma das variáveis, confirmando que a variabilidade intra-observador foi mantida dentro do nível de aceitação. O erro aleatório, definido de acordo com a fórmula de Dahlberg $\left(\sqrt{ } \sum \mathrm{d}^{2} / 2 \mathrm{n}\right)$, variou de 0,1 (variável INCNA) a 0,9 (variável ANVERT).

\section{Análise estatística}

Todas as medidas provenientes do programa DFPlus (DFPlus: Dentofacial Software Inc.,1995. 1 First Canadian Place, Suite 870 Toronto, Ontario, Canada, M5X 1C9.) foram digitalizadas no programa SPSS (10.0) (SPSS

\begin{tabular}{|c|c|c|c|}
\hline \multicolumn{3}{|c|}{$\begin{array}{c}\text { Tabela 1A - Média e desvio padrão para as } \\
\text { variáveis estudadas, considerando-se todos } \\
\text { os pacientes antes do procedimento cirúrgico (T1). }\end{array}$} \\
\hline $\begin{array}{c}\text { Variáveis } \\
\text { (T1) }\end{array}$ & $\begin{array}{c}\text { Número de } \\
\text { pacientes }\end{array}$ & Média & Desvio Padrão \\
\hline SNA & 19 & 79,0 & 6,1 \\
\hline INCNA & 19 & 30,7 & 10,1 \\
\hline SNPO & 19 & 13,9 & 6,6 \\
\hline ANVERT & 19 & $-0,9$ & 7,0 \\
\hline NASO & 19 & 98,3 & 13,3 \\
\hline EIXOY & 19 & 93,6 & 3,8 \\
\hline LSEST & 19 & $-7,5$ & 2,9 \\
\hline LSBUR & 19 & 1,9 & 1,7 \\
\hline LIEST & 19 & $-2,3$ & 2,8 \\
\hline LIBUR & 19 & 4,0 & 2,2 \\
\hline ALTLA & 19 & 23,2 & 4,3 \\
\hline
\end{tabular}

Release 10.0444 N. Michigan Av, Chicago, Illinois 60611, USA.) para análise. Distribuições normais foram verificadas para todas variáveis. Médias e desvios padrão foram calculados para todas as variáveis, agrupando todos os pacientes e separando-os por grau de movimentação ântero-posterior (AP 1 e AP 2) ou rotação do plano oclusal (ROT 1 e ROT 2). Testes t de Student pareados foram aplicados para cada par de variáveis (final - inicial), considerando todos os pacientes da amostra e separando-os por grau de movimentação ântero-posterior (AP 1 e AP 2) ou rotação do plano oclusal (ROT 1 e ROT 2), com nível de significância de $p \leq 0,05$. Testes de correlação de Pearson (bi-variável) foram aplicados entre todas variáveis considerando todos os pacientes da amostra, com nível de significância de $\mathrm{p} \leq 0,05$.

\section{RESULTADOS}

As onze variáveis foram estudadas em todos os pacientes e suas médias e desvios padrão estão descritos nas tabelas 1A (inicial) e 1B (final).

De acordo com a quantidade de movimentação sofrida pela maxila no ato cirúrgico, os pacientes foram divididos de acordo com duas características:

\begin{tabular}{|c|c|c|c|}
\hline \multicolumn{4}{|c|}{$\begin{array}{c}\text { Tabela 1B - Média e desvio padrão para as } \\
\text { variáveis estudadas, considerando-se todos } \\
\text { os pacientes depois do procedimento cirúrgico (T2). }\end{array}$} \\
\hline $\begin{array}{l}\text { Variáveis } \\
\text { (T2) }\end{array}$ & $\begin{array}{c}\text { Número de } \\
\text { pacientes }\end{array}$ & Média & Desvio Padrão \\
\hline SNA & 19 & 84,3 & 6,1 \\
\hline INCNA & 19 & 20,6 & 8,9 \\
\hline SNPO & 19 & 15,3 & 5,0 \\
\hline ANVERT & 19 & 2,7 & 5,9 \\
\hline NASO & 19 & 104,0 & 7,0 \\
\hline EIXOY & 19 & 94,2 & 4,0 \\
\hline LSEST & 19 & $-5,3$ & 3,3 \\
\hline LSBUR & 19 & 3,1 & 2,1 \\
\hline LIEST & 19 & $-3,1$ & 3,4 \\
\hline LIBUR & 19 & 2,4 & 2,7 \\
\hline ALTLA & 19 & 25,5 & 4,2 \\
\hline
\end{tabular}


1) Diferença entre SNA inicial e SNA final, o que representa o quanto a maxila foi deslocada horizontalmente no sentido ântero-posterior. Se a diferença foi menor que $4^{\circ}$, o paciente foi alocado no grupo AP (ântero-posterior) 1, e descrito nas tabelas 2A (inicial) e 2B (final). Se a diferença foi maior que $4^{\circ}$, o paciente foi alocado no grupo AP 2 ,

\begin{tabular}{|c|c|c|c|}
\hline \multicolumn{4}{|c|}{$\begin{array}{c}\text { Tabela 2A - Média e desvio padrão para as variáveis } \\
\text { estudadas, considerando-se os pacientes com menor } \\
\text { deslocamento ântero-posterior (AP 1), antes do procedi- } \\
\text { mento cirúrgico (T1). }\end{array}$} \\
\hline $\begin{array}{l}\text { Variáveis } \\
\text { (T1) }\end{array}$ & $\begin{array}{l}\text { Número de } \\
\text { pacientes }\end{array}$ & Média & Desvio Padrão \\
\hline SNA & 10 & 78,9 & 7,7 \\
\hline INCNA & 10 & 33,5 & 6,6 \\
\hline SNPO & 10 & 10,6 & 6,4 \\
\hline ANVERT & 10 & $-4,4$ & 3,8 \\
\hline NASO & 10 & 98,8 & 10,6 \\
\hline EIXOY & 10 & 93,1 & 4,3 \\
\hline LSEST & 10 & $-7,3$ & 3,9 \\
\hline LSBUR & 10 & 2,3 & 1,7 \\
\hline LIEST & 10 & $-2,5$ & 3,5 \\
\hline LIBUR & 10 & 3,7 & 2,4 \\
\hline ALTLA & 10 & 24,1 & 3,2 \\
\hline
\end{tabular}

\begin{tabular}{|c|c|c|c|}
\hline \multicolumn{4}{|c|}{$\begin{array}{c}\text { Tabelas 3A - Média e desvio padrão para as variáveis } \\
\text { estudadas, considerando-se os pacientes com maior } \\
\text { deslocamento ântero-posterior (AP 2), antes do procedi- } \\
\text { mento cirúrgico (T1). }\end{array}$} \\
\hline $\begin{array}{l}\text { Variáveis } \\
\text { (T1) }\end{array}$ & $\begin{array}{l}\text { Número de } \\
\text { pacientes }\end{array}$ & Média & Desvio Padrão \\
\hline SNA & 9 & 79,2 & 8,3 \\
\hline INCNA & 9 & 27,6 & 12,6 \\
\hline SNPO & 9 & 17,5 & 4,8 \\
\hline ANVERT & 9 & 3,1 & 7,9 \\
\hline NASO & 9 & 97,8 & 16,5 \\
\hline EIXOY & 9 & 94,1 & 3,3 \\
\hline LSEST & 9 & $-7,6$ & 1,6 \\
\hline LSBUR & 9 & 1,9 & 1,2 \\
\hline LIEST & 9 & $-2,2$ & 1,8 \\
\hline LIBUR & 9 & 4,4 & 2,0 \\
\hline ALTLA & 9 & 22,3 & 5,2 \\
\hline
\end{tabular}

descritos nas tabelas 3A (inicial) e 3B (final).

2) Diferença na angulação do plano palatino inicial e final, o que representa a quantidade de rotação sofrida pela maxila durante o procedimento cirúrgico. Se a diferença foi menor que $2^{\circ}$, o paciente foi alocado no grupo ROT 1, e descrito nas tabelas 4A (inicial) e 4B (final). Se a diferença foi maior que $2^{\circ}$,

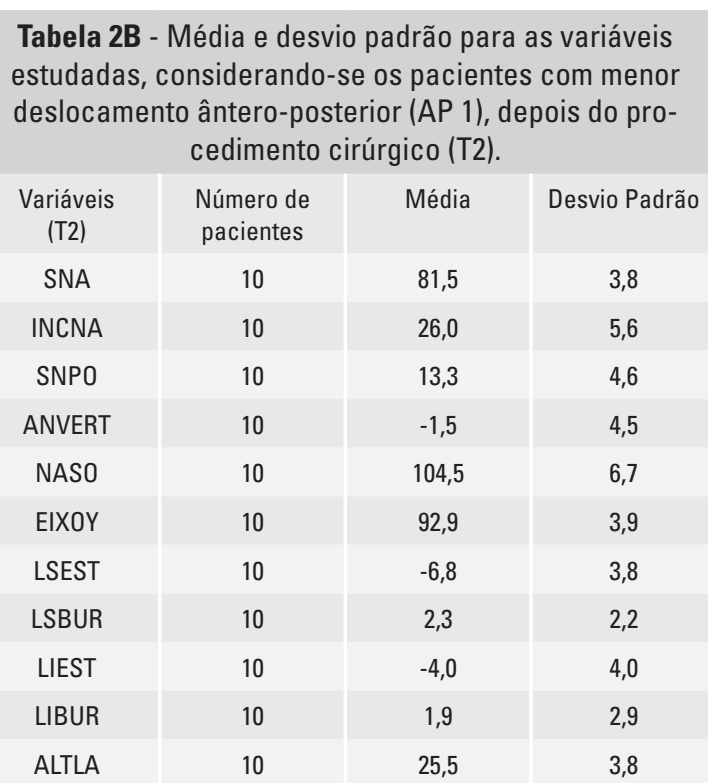

Tabelas 3B - Média e desvio padrão para as variáveis estudadas, considerando-se os pacientes com maior deslocamento ântero-posterior (AP 2), depois do procedimento cirúrgico (T2).

\begin{tabular}{|c|c|c|c|}
\hline $\begin{array}{c}\text { Variáveis } \\
\text { (T2) }\end{array}$ & $\begin{array}{c}\text { Número de } \\
\text { pacientes }\end{array}$ & Média & Desvio Padrão \\
\hline SNA & 9 & 87,4 & 6,8 \\
\hline INCNA & 9 & 14,5 & 8,1 \\
\hline SNPO & 9 & 17,6 & 4,8 \\
\hline ANVERT & 9 & 7,5 & 3,3 \\
\hline NASO & 9 & 103,0 & 7,7 \\
\hline EIXOY & 9 & 95,7 & 3,7 \\
\hline LSEST & 9 & $-3,8$ & 2,1 \\
\hline LSBUR & 9 & 4,0 & 1,6 \\
\hline LIEST & 9 & $-2,1$ & 2,4 \\
\hline LIBUR & 9 & 2,9 & 2,5 \\
\hline ALTLA & 9 & 25,5 & 4,9 \\
\hline
\end{tabular}


o paciente foi alocado no grupo ROT 2, e descrito nas tabelas 5A (inicial) e 5B (final).

Quando todos os pacientes foram considerados, houve diferenças estatisticamente significativas entre as radiografias T1 e T2 para SNA, INCNA, ANVERT, LSEST, LIBUR e ALTLA, mas não para SNPO, NASO, EIXOY, LIEST e LSBUR (Tab. 6).

As correlações de Pearson (r) e seus respectivos níveis de significância (p) para todas as variá-

\begin{tabular}{|c|c|c|c|}
\hline $\begin{array}{l}\text { Variáveis } \\
\text { (T1) }\end{array}$ & $\begin{array}{l}\text { Número de } \\
\text { pacientes }\end{array}$ & Média & Desvio Padrão \\
\hline SNA & 10 & 78,1 & 8,1 \\
\hline INCNA & 10 & 30,2 & 11,9 \\
\hline SNPO & 10 & 16,8 & 4,9 \\
\hline ANVERT & 10 & 1,2 & 9,0 \\
\hline NASO & 10 & 97,3 & 15,5 \\
\hline EIXOY & 10 & 94,0 & 3,1 \\
\hline LSEST & 10 & $-7,8$ & 1,5 \\
\hline LSBUR & 10 & 2,0 & 1,1 \\
\hline LIEST & 10 & $-2,5$ & 2,1 \\
\hline LIBUR & 10 & 4,0 & 2,3 \\
\hline ALTLA & 10 & 22,4 & 5,3 \\
\hline
\end{tabular}

Tabela 5A - Média e desvio padrão para as variáveis estudadas, considerando-se os pacientes com maior rotação do plano oclusal (ROT 2), antes do procedimento cirúrgico (T1).

\begin{tabular}{|c|c|c|c|}
\hline $\begin{array}{c}\text { Variáveis } \\
\text { (T1) }\end{array}$ & $\begin{array}{c}\text { Número de } \\
\text { pacientes }\end{array}$ & Média & Desvio Padrão \\
\hline SNA & 9 & 80,2 & 2,6 \\
\hline INCNA & 9 & 31,3 & 8,3 \\
\hline SNPO & 9 & 10,6 & 7,0 \\
\hline ANVERT & 9 & $-3,2$ & 3,1 \\
\hline NASO & 9 & 99,4 & 11,3 \\
\hline EIXOY & 9 & 93,1 & 4,6 \\
\hline LSEST & 9 & $-7,1$ & 4,1 \\
\hline LSBUR & 9 & 2,3 & 1,9 \\
\hline LIEST & 9 & $-2,0$ & 3,6 \\
\hline LIBUR & 9 & 4,0 & 2,1 \\
\hline ALTLA & 9 & 24,2 & 2,6 \\
\hline
\end{tabular}

veis considerando todos os pacientes são descritos na tabela 7 .

A movimentação anterior da maxila foi correlacionada com a rotação horária do plano oclusal (SNA e SNOP) e inclinação dos incisivos superiores (SNA e INCNA).

O ângulo naso-labial foi correlacionado com a retro-inclinação dos incisivos superiores e a posição da maxila (INCNA e NASO; ANVERT e NASO).

\begin{tabular}{|c|c|c|c|}
\hline $\begin{array}{l}\text { Variáveis } \\
\text { (T2) }\end{array}$ & $\begin{array}{l}\text { Número de } \\
\text { pacientes }\end{array}$ & Média & Desvio Padrão \\
\hline SNA & 10 & 85,6 & 7,8 \\
\hline INCNA & 10 & 17,6 & 9,3 \\
\hline SNPO & 10 & 16,5 & 4,5 \\
\hline ANVERT & 10 & 5,4 & 6,4 \\
\hline NASO & 10 & 102,6 & 6,0 \\
\hline EIXOY & 10 & 95,8 & 3,8 \\
\hline LSEST & 10 & $-4,9$ & 2,1 \\
\hline LSBUR & 10 & 3,4 & 1,9 \\
\hline LIEST & 10 & $-3,1$ & 1,9 \\
\hline LIBUR & 10 & 2,2 & 2,2 \\
\hline ALTLA & 10 & 25,3 & 5,5 \\
\hline
\end{tabular}

Tabela 5B - Média e desvio padrão para as variáveis estudadas, considerando-se os pacientes com maior rotação do plano oclusal (ROT 2), depois do procedimento cirúrgico (T2).

\begin{tabular}{|c|c|c|c|}
\hline $\begin{array}{c}\text { Variáveis } \\
\text { (T2) }\end{array}$ & $\begin{array}{c}\text { Número de } \\
\text { pacientes }\end{array}$ & Média & Desvio Padrão \\
\hline SNA & 9 & 82,8 & 3,1 \\
\hline INCNA & 9 & 23,9 & 7,6 \\
\hline SNPO & 9 & 14,1 & 5,6 \\
\hline ANVERT & 9 & $-0,2$ & 3,5 \\
\hline NASO & 9 & 105,6 & 8,1 \\
\hline EIXOY & 9 & 92,5 & 3,4 \\
\hline LSEST & 9 & $-5,8$ & 4,5 \\
\hline LSBUR & 9 & 2,8 & 2,4 \\
\hline LIEST & 9 & $-3,1$ & 4,7 \\
\hline LIBUR & 9 & 2,6 & 3,2 \\
\hline ALTLA & 9 & 25,7 & 2,5 \\
\hline
\end{tabular}




\begin{tabular}{|c|c|c|c|c|c|c|}
\hline \multirow{2}{*}{ Variáveis } & \multicolumn{2}{|c|}{ Inicial (T1) } & \multicolumn{2}{|c|}{ Final (T2) } & \multicolumn{2}{|c|}{ Mudança (T1-T2) } \\
\hline & Média & DP & Média & DP & Média & DP \\
\hline SNA & 79,0 & 6,1 & 84,3 & 6,1 & $5,2 * *$ & 3,7 \\
\hline INCNA & 30,7 & 10,1 & 20,6 & 8,9 & $-10,1^{* *}$ & 5,6 \\
\hline SNPO & 13,9 & 6,6 & 15,3 & 5,0 & 1,4 & 3,3 \\
\hline ANVERT & $-0,9$ & 7,0 & 2,7 & 5,9 & $3,6^{*}$ & 4,9 \\
\hline NASO & 98,3 & 13,3 & 104,0 & 7,0 & 5,7 & 15,1 \\
\hline EIXOY & 93,6 & 3,8 & 94,2 & 4,0 & 0,6 & 2,8 \\
\hline LSEST & $-7,5$ & 2,9 & $-5,3$ & $-3,3$ & $2,2^{* *}$ & 2,3 \\
\hline LSBUR & 2,1 & $-1,5$ & 3,1 & 2,1 & $1,0^{*}$ & 2,1 \\
\hline LIEST & $-2,3$ & 2,8 & $-3,1$ & 2,7 & 0,8 & 1,7 \\
\hline LIBUR & 4,0 & 2,2 & 2,4 & 3,4 & $1,6^{*}$ & 1,8 \\
\hline ALTLA & 23,2 & 4,3 & 25,5 & 4,2 & $2,3^{*}$ & 2,7 \\
\hline
\end{tabular}

\begin{tabular}{|c|c|c|c|c|c|c|c|c|c|}
\hline Variáveis & INCNA & SNPO & ANVERT & NASO & LSEST & LSBUR & LIEST & LIBUR & ALTLA \\
\hline \multirow[t]{2}{*}{ SNA } & $-0,55$ & $-0,52$ & $-0,08$ & 0,14 & 0,63 & 0,29 & 0,15 & $-0,25$ & 0,54 \\
\hline & $0,02^{*}$ & $0,02^{*}$ & 0,76 & 0,58 & $0,01^{* *}$ & 0,23 & 0,55 & 0,30 & $0,18^{*}$ \\
\hline \multirow[t]{2}{*}{ INCNA } & & 0,24 & 0,31 & $-0,50$ & $-0,20$ & 0,13 & $-0,12$ & 0,19 & $-0,60$ \\
\hline & & 0,33 & 0,19 & $0,03^{*}$ & 0,42 & 0,59 & 0,62 & 0,62 & $0,01^{* *}$ \\
\hline \multirow[t]{2}{*}{ SNPO } & & & $-0,13$ & 0,21 & $-0,13$ & $-0,39$ & 0,22 & 0,34 & 0,16 \\
\hline & & & 0,61 & 0,40 & 0,59 & 0,88 & 0,36 & 0,15 & 0,53 \\
\hline \multirow[t]{2}{*}{ ANVERT } & & & & $-0,65$ & $-0,26$ & 0,41 & 0,09 & 0,26 & $-0,29$ \\
\hline & & & & $0,02^{* *}$ & 0,29 & 0,81 & 0,71 & 0,29 & 0,23 \\
\hline \multirow[t]{2}{*}{ NASO } & & & & & $-0,20$ & $-0,55$ & 0,05 & $-0,37$ & 0,44 \\
\hline & & & & & 0,41 & $0,014^{*}$ & 0,83 & 0,16 & 0,06 \\
\hline \multirow[t]{2}{*}{ LSEST } & & & & & & 0,75 & 0,54 & 0,30 & 0,19 \\
\hline & & & & & & $0,01^{* *}$ & $0,02^{*}$ & 0,21 & 0,43 \\
\hline \multirow[t]{2}{*}{ LSBUR } & & & & & & & 0,46 & 0,51 & $-0,80$ \\
\hline & & & & & & & $0,05^{*}$ & $0,02^{*}$ & 0,75 \\
\hline \multirow[t]{2}{*}{ ALTLA } & & & & & & & 0,15 & $-0,12$ & 1,00 \\
\hline & & & & & & & 0,55 & 0,60 & 0,00 \\
\hline
\end{tabular}

O aumento na altura labial foi correlacionado com a movimentação anterior da maxila (ALTLA e SNA) e retro-inclinação dos incisivos superiores (ALTLA e INCNA).

A movimentação anterior da maxila foi correlacionada com a linha estética (SNA e LSEST). A relação entre a movimentação do lábio superior e a movimentação da maxila foi de aproximadamente 0,6 , considerando-se a movimentação anterior da maxila (ANVERT) e a linha estética (LSEST), descritos na tabela 6 .

Não houve significativa correlação entre a base maxilar e a linha de Burstone (SNA e LSBUR). O ângulo naso-labial apresentou uma correlação negativa com a linha de Burstone (NASO e LSBUR). Houve significativa correlação entre a linha estética e a linha de Burstone, tanto para o lábio superior (LSEST e LSBUR), como para o lábio inferior (LIEST e LIBUR).

Quando as alterações ântero-posteriores foram menores (grupo AP 1, Tab. 8) não houve alterações estéticas significativas. Houve diferenças estatisticamente significativas entre as radiografias $\mathrm{T} 1$ e $\mathrm{T} 2$ para SNA, INCNA, SNPO, ANVERT, LIEST e LIBUR mas não para NASO, EIXOY, LSEST, LSBUR e ALTLA (Tab. 8).

Alterações ântero-posteriores maiores (grupo AP 2, Tab. 9) 
e também observadas na tabela 10 (ROT 1) influenciaram significativamente a posição ântero-posterior e também a altura do lábio superior. Quando somente o grupo AP 2 foi estudado, houve diferenças estatisticamente significativas entre as radiografias $\mathrm{Tl}$ e T2 para SNA, INCNA, LSEST, LSBUR, ALTLA mas não para SNPO, ANVERT, NASO, EIXOY, LIEST e LIBUR (Tab. 9).

Quando somente o grupo ROT 1 foi estudado (Tab. 10), houve diferenças estatisticamente signifi- cativas entre as radiografias T1 e T2 para SNA, INCNA, EIXOY, LSEST, LSBUR. LIBUR e ALTLA mas não para SNPO, ANVERT, NASO e LIEST.

A rotação horária não influenciou significativamente a altura do lábio superior. Quando somente o grupo ROT 2 foi estudado (Tab. 11), houve diferenças estatisticamente significativas entre as radiografias T1 e T2 para SNA, INCNA, SNPO, ANVERT e LIBUR mas não para, NASO, EIXOY, LSEST, LSBUR, LIEST e ALTLA.

\begin{tabular}{|c|c|c|c|c|c|c|}
\hline \multicolumn{7}{|c|}{ Tabela 8 - Teste t de Student entre T1 e T2, no grupo AP 1} \\
\hline \multirow[t]{2}{*}{ Variáveis } & \multicolumn{2}{|c|}{ Inicial (T1) } & \multicolumn{2}{|c|}{ Final (T2) } & \multicolumn{2}{|c|}{ Mudança (T1-T2) } \\
\hline & Média & DP & Média & DP & Média & DP \\
\hline SNA & 78,9 & 7,7 & 81,5 & 3,8 & $2,5^{*}$ & 1,6 \\
\hline INCNA & 33,5 & 6,6 & 26,0 & 5,6 & $-7,5^{* *}$ & 3,7 \\
\hline SNPO & 10,6 & 6,4 & 13,3 & 4,6 & $2,7^{*}$ & 3,7 \\
\hline ANVERT & $-4,4$ & 3,8 & $-1,5$ & 4,5 & $2,9^{*}$ & 2,0 \\
\hline NASO & 98,8 & 10,6 & 104,5 & 6,7 & 5,7 & 11,8 \\
\hline EIXOY & 93,1 & 4,3 & 92,9 & 3,9 & $-0,2$ & 2,8 \\
\hline LSEST & $-7,3$ & 3,9 & $-6,8$ & 3,8 & 0,5 & 1,7 \\
\hline LSBUR & 2,3 & 1,7 & 2,3 & 2,2 & 0,1 & 2,0 \\
\hline LIEST & $-2,5$ & 3,5 & $-4,0$ & 4,0 & $1,5^{*}$ & 1,3 \\
\hline LIBUR & 3,7 & 2,4 & 1,9 & 2,9 & $1,8^{*}$ & 1,5 \\
\hline ALTLA & 24,1 & 3,2 & 25,5 & 3,8 & 1,4 & 2,3 \\
\hline
\end{tabular}

\begin{tabular}{|c|c|c|c|c|c|c|}
\hline \multicolumn{5}{|c|}{ Tabela 9 - Teste t de Student entre T1 e T2, no grupo AP 2. } \\
\hline Variáveis & \multicolumn{2}{|c|}{ Inicial (T1) } & \multicolumn{2}{|c|}{ Final (T2) } & \multicolumn{2}{c|}{ Mudança (T1-T2) } \\
& Média & DP & Média & DP & Média & DP \\
\hline SNA & 79,2 & 8,3 & 87,4 & 6,8 & $8,2^{* *}$ & 2,9 \\
\hline INCNA & 27,6 & 12,6 & 14,5 & 8,1 & $-13,3^{* *}$ & 6,0 \\
\hline SNPO & 17,5 & 4,8 & 17,6 & 4,8 & 0,1 & 2,1 \\
\hline ANVERT & 3,1 & 7,9 & 7,5 & 3,3 & 4,4 & 7,0 \\
\hline NASO & 97,8 & 16,5 & 103,0 & 7,7 & 5,7 & 18,9 \\
\hline EIXOY & 94,1 & 3,3 & 95,7 & 3,7 & 1,5 & 2,7 \\
\hline LSEST & $-7,6$ & 1,6 & $-3,8$ & 2,1 & $3,8^{* *}$ & 1,6 \\
\hline LSBUR & 1,9 & 1,2 & 4,0 & 1,6 & $2,2^{*}$ & 1,6 \\
\hline LIEST & $-2,2$ & 1,8 & $-2,1$ & 2,4 & $-0,1$ & 1,9 \\
\hline LIBUR & 4,4 & 2,0 & 2,9 & 2,5 & 1,5 & 2,1 \\
\hline ALTLA & 22,3 & 5,2 & 25,5 & 4,9 & $3,2^{*}$ & 3,0 \\
\hline
\end{tabular}

${ }^{*} p<0,05 ;{ }^{* *} p<0,01$ 


\begin{tabular}{|c|c|c|c|c|c|c|}
\hline \multicolumn{5}{|c|}{ Tabela 10 - Teste t de Student entre T1 e T2, no grupo ROT 1 } \\
\hline Variáveis & \multicolumn{2}{|c|}{ Inicial (T1) } & \multicolumn{2}{|c|}{ Final (T2) } & \multicolumn{2}{|c|}{ Mudança (T1-T2) } \\
\hline & Média & DP & Média & DP & Média & DP \\
\hline SNA & 78,1 & 8,1 & 85,6 & 7,8 & $7,6^{* *}$ & 3,4 \\
\hline INCNA & 30,2 & 11,9 & 17,6 & 9,3 & $-12,5^{* *}$ & 5,9 \\
\hline SNPO & 16,8 & 4,9 & 16,5 & 4,5 & $-0,4$ & 1,0 \\
\hline ANVERT & 1,2 & 9,0 & 5,4 & 6,4 & 4,2 & 6,5 \\
\hline NASO & 97,3 & 15,5 & 102,6 & 6,0 & 5,3 & 17,7 \\
\hline EIXOY & 94,0 & 3,1 & 95,8 & 3,8 & $1,8^{*}$ & 2,2 \\
\hline LSEST & $-7,8$ & 1,5 & $-4,9$ & 2,1 & $2,9^{* *}$ & 1,9 \\
\hline LSBUR & 2,0 & 1,1 & 3,4 & 1,9 & $1,4^{*}$ & 1,9 \\
\hline LIEST & $-2,5$ & 2,1 & $-3,1$ & 1,9 & 0,6 & 1,6 \\
\hline LIBUR & 4,0 & 2,3 & 2,2 & 2,2 & $1,8^{*}$ & 1,8 \\
\hline ALTLA & 22,4 & 5,3 & 25,3 & 5,5 & $2,9^{*}$ & 3,0 \\
\hline *0 0 0,05; **p $<0,01$ & & & & & \\
\hline
\end{tabular}

\begin{tabular}{|c|c|c|c|c|c|c|}
\hline \multicolumn{5}{|c|}{ Tabela 11 - Teste t de Student entre T1 e T2, no grupo ROT 2 } \\
\hline Variáveis & \multicolumn{2}{|c|}{ Inicial (T1) } & \multicolumn{2}{|c|}{ Final (T2) } & \multicolumn{2}{|c|}{ Mudança (T1-T2) } \\
\hline & Média & DP & Média & DP & Média & DP \\
\hline SNA & 80,2 & 2,6 & 82,8 & 3,1 & $2,6^{*}$ & 1,8 \\
\hline INCNA & 31,3 & 8,3 & 23,9 & 7,6 & $-7,5^{* *}$ & 3,9 \\
\hline SNPO & 10,6 & 7,0 & 14,1 & 5,6 & $3,4^{*}$ & 3,8 \\
\hline ANVERT & $-3,2$ & 3,1 & $-0,2$ & 3,5 & $3,0^{*}$ & 2,1 \\
\hline NASO & 99,4 & 11,3 & 105,6 & 8,1 & 6,1 & 12,6 \\
\hline EIXOY & 93,1 & 4,6 & 92,5 & 3,4 & $-0,6$ & 2,9 \\
\hline LSEST & $-7,1$ & 4,1 & $-5,8$ & 4,5 & $-1,3$ & 2,5 \\
\hline LSBUR & 2,3 & 1,9 & 2,8 & 2,4 & 0,6 & 2,4 \\
\hline LIEST & $-2,0$ & 3,7 & $-3,1$ & 4,7 & 1,1 & 1,9 \\
\hline LIBUR & 4,0 & 2,1 & 2,6 & 3,2 & $1,4^{*}$ & 1,8 \\
\hline ALTLA & 24,2 & 2,6 & 25,7 & 2,5 & 1,6 & 2,3 \\
\hline *p $<0,05 ; ~ * * p<0,01$ & & & & & & \\
\hline
\end{tabular}

xilares, nossos resultados também apresentaram significativa variação. Em primeiro lugar, porque o problema naturalmente envolve muita variação. Os pacientes que são submetidos a esse tipo de procedimento cirúrgico não apresentam insignificativas discrepâncias dento-alveolares. Se selecionarmos os grupos por tipos de deficiência, nossa amostra será cada vez menor, dificultando a aplicação de testes estatísticos.

Mesmo dividindo-se a amostra em casos que apresentavam menores ou maiores discrepâncias ântero-posteriores ${ }^{26,39}$ significantes desvios padrão demonstram que a dificuldade de homogeneização persiste.

O mesmo ocorre quando dividimos a amostra em menores ou maiores rotações do plano oclusal em relação à base craniana anterior, durante $\mathrm{o}$ procedimento cirúrgico.

Como quanto aos resultados ortodônticos, a literatura não provém resultados cirúrgicos definitivos. O lábio superior se move anteriormente numa proporção de $0,4^{1}, 0,5^{17,32}, 0,6^{8}$,

A divisão da amostra em grupos com alterações menores e maiores, conforme sugerido por Wisth ${ }^{39}$, não reduziu significativamente a variação apresentada inicialmente.

Análises de regressão múltipla ${ }^{1}$ também já foram utilizadas com esse objetivo e não melhoraram a predictibilidade da resposta dos tecidos moles.

Embora tenhamos limitado nossa amostra a pacientes que sofreram somente intervenções ma-
$0,7^{7,31,35}$ ou $0,8^{32}$ quando a base maxilar é movida anteriormente. Correlações verticais são também imprecisas $^{8}$ e podem apresentar a relação de 0,4 entre tecidos moles e tecidos duros ${ }^{7,26,31}$, de 0,2 a $0,5^{32}$ ou $0,6^{8}$.

Nossos resultados mostram que a movimentação anterior da maxila é um movimento horizontal e vertical combinado, como descrito por Bell e Dann $^{7}$. A movimentação anterior da maxila pode ser correlacionada com a rotação horária do plano 
oclusal, influenciando a inclinação dos incisivos superiores, que são rotacionados para baixo e para trás. Isso provoca um aumento no ângulo naso-labial e aumento na altura labial.

Quando a base óssea maxilar é movida para frente, há uma significante diminuição da distância entre os incisivos superiores e a linha estética. A relação entre a movimentação ântero-posterior do lábio superior e a movimentação da maxila é de aproximadamente 0,6 , considerando-se a distância da maxila (Ponto A) à linha NVERT e a linha estética (LSEST), ou seja, dividido-se LSEST por ANVERT (Tab. 6). A variável ANVERT apresentou um desvio padrão muito significativo, o que provavelmente impediu sua correlação com LSEST e LSBUR (Tab. 7).

Embora as correlações entre SNA e LSEST sejam melhores, sendo $0,63(\mathrm{p}<0,01)$ para SNA e LSEST e 0,54 $(\mathrm{p}<0,05)$ para SNA e ALTLA; SNA não pode ser relacionado à LSEST e ALTLA pois é de uma grandeza diferente, sendo expressa em graus e as outras em milímetros. Verticalmente, a relação entre o aumento da altura do lábio superior (ALTLA) e a movimentação da maxila (ANVERT) foi também de aproximadamente 0,6 (ALTLA dividido por ANVERT, Tab. 6).

Não houve significativa correlação entre a base maxilar e a linha de Burstone (SNA e LSBUR) provavelmente porque a referência dessa linha (ângulo naso-labial) também se moveu consideravelmente para frente com a movimentação da base maxilar e as modificações da distância do lábio superior à LSBUR foram pequenas (em média 1,0 mm, Tab. 6).

A correlação negativa de NASO com LBUR, uma vez que o ângulo naso-labial diminuiu com o aumento de LSBUR (Tab. 6 e 7), faz sentido clinicamente, entretanto, o ângulo naso-labial (NASO) aumentou em média, por conta da significante variação envolvida.

A linha estética e a linha de Burstone naturalmente se correlacionam para o lábio superior
(LSEST e LSBUR) e para o lábio inferior (LIEST e LIBUR) porque medem a mesma estrutura, ou seja, respectivamente a projeção anterior dos lábios superior e inferior.

Dos fatores envolvidos, talvez o mais importante seja a espessura dos lábios 7,18,20,30,32. Ao mesmo tempo, sabe-se que a medição objetiva de um componente muscular é inatingível na prática ${ }^{24}$. Medições em radiografias dependem diretamente do posicionamento dos lábios durante a tomada radiográfica, introduzindo, da mesma forma, importante variação. Técnicas mais sofisticadas com vídeo-imagem $^{34}$ ou radiografias dinâmicas ${ }^{21}$ podem fornecer melhores respostas.

A análise de todos os pacientes mostra que as cirurgias foram eficazes no seu objetivo inicial, movimentando significativamente a maxila, demonstrado pela alteração na posição da base óssea maxilar em relação à base craniana anterior e inclinação dos incisivos superiores em relação à base óssea maxilar. Não houve significância estatística para as alterações do ângulo naso-labial, provavelmente devido à variação envolvida, evidente pelo desvio padrão apresentado.

Em nosso estudo, as mudanças estéticas no lábio superior ocorreram quando as alterações ântero-posteriores ou verticais nos tecidos duros foram significativas, concordando com os resultados de Shelly et al. ${ }^{37}$, que afirmaram que somente casos com acentuada discrepância esquelética podem apresentar resultados estéticos significativos.

Quando os grupos foram analisados separadamente, apenas dois casos apresentaram alterações ântero-posteriores e verticais menores (casos 5 e 16) e apenas um caso sofreu alterações ânteroposteriores e verticais maiores (caso 9), impossibilitando que testes estatísticos pudessem ser aplicados nessas situações. Em todos os outros dezesseis casos, quando as alterações ântero-posteriores foram menores, as verticais foram maiores ou vice-versa. Isso é coerente com a indicação do procedimento, uma vez que um caso é classificado como cirúrgico se apresentar no mínimo alguma 
discrepância significativa, seja ântero-posterior ou vertical.

Quando os casos com menor alteração ântero-posterior (AP 1) são considerados (Tab. 7), observa-se que as mudanças no lábio superior (LSEST e LSBUR) não são significativas, bem como a alteração na altura do lábio superior (ALTLA), embora a inclinação do plano oclusal, possa permitir maior acomodação do lábio inferior e conseqüentemente LIEST e LIBUR são estatisticamente significantes.

Quando os pacientes que sofreram alterações ântero-posteriores mais significativas foram considerados (Tab. 8), a alteração da base maxilar em relação à base craniana (SNA) é mantida, bem como a inclinação dos incisivos superiores. As alterações no lábio superior, horizontais ou verticais, são estatisticamente significantes. Porém, para o lábio inferior os resultados não foram significativos. Provavelmente porque as linhas de referência (estética e de Burstone) se moveram para frente na sua parte superior (ângulo naso-labial e ponta do nariz) e camuflaram as alterações posteriores do lábio inferior. Maior projeção do lábio superior condiz com o padrão de estética atual, tanto para mulheres ${ }^{2}$, como para homens ${ }^{29}$.

Quando os pacientes sofreram pequena rotação do plano oclusal (ROT 1, Tab. 9), ocorre significativa alteração da base maxilar (SNA) e inclinação dos incisivos superiores (INCNA), bem como alterações estéticas significativas (LSEST, LSBUR, LIBUR e ALTLA), reproduzindo a mesma situação do grupo AP 2.

Isso foi confirmado pela alocação dos pacientes em seus grupos. Com exceção de um, todos os pacientes que foram alocados no grupo AP 2 foram também alocados no grupo ROT 1, ou seja, quando houve significativa movimentação ânteroposterior da maxila, sua rotação horária foi inevitável.

Quando a rotação do plano oclusal é significativa (Tab. 10), as alterações em tecidos moles (LSEST, LSBUR e ALTLA) deixam de ser significativas, embora as alterações esqueléticas (SNA, ANVERT e SNPO) e dentárias (INCNA) sejam significativas.

Isso sugere que a rotação do plano oclusal não é decisiva para a projeção ântero-posterior ou verticais do lábio superior, mas permitem que o lábio inferior, que estava evertido, seja retroposicionado e possibilite melhor selamento dos lábios.

\section{CONCLUSÕES}

Baseando-se nos resultados apresentados, podemos concluir que:

1) Significativas alterações horizontais ocorrem no lábio superior quando a base maxilar é movimentada significativamente ântero-posteriormente, na proporção aproximada de 0,6:1.

2) O movimento anterior da maxila é geralmente acompanhado do movimento vertical para baixo, mesmo não havendo significativa alteração do plano oclusal.

3) Alterações verticais no lábio superior ocorrem somente quando há significativa alteração na posição ântero-posterior da base óssea maxilar e rotações do plano oclusal sem significativas alterações ântero-posteriores não proporcionam significativas mudanças verticais no lábio superior.

4) A movimentação ântero-inferior da maxila promove alterações significativas no lábio inferior, proporcionando melhor selamento labial. 


\title{
Changes in the lip profile of patients that undergone Le Fort I maxillary orthognathic surgery
}

\begin{abstract}
The literature has described that the predictability of the outcomes of orthognatic corrections in soft tissues is limited, because it shows significant variation and it does not offer final conclusions, limiting its clinical applications. The goal of this article is to retrospectively study the effects of maxillary orthognathic surgeries, Le Fort I type, in upper and lower lips of adult patients. Moreover, it intends to discuss the problems involved in this research area. The sample was constituted of 19 Caucasian adults, aging from 19 to 42 year-old, beingl0 male and 9 female, that undergone maxillary orthognathic surgery in CEDEFACE (Araraquara - SP). The vast majority of the cases presented a significant discrepancy, antero posterior, vertical or both, reinforcing its surgical recommendation. Significant changes in soft tissues were observed when skeletal changes, antero posterior or vertical, were significant. The proportion of approximately $0.6: 1$ soft to hard tissue changes was observed in the upper lip. Vertical changes in the maxilla without significant horizontal changes were not sufficient to vertically increase the upper lip size. Antero posterior changes in the lower lip as a consequence of the forward and downward maxillary relocation allow better lip posture. Vertical changes in the lower lip were not quantified.

Key words: Maxillary surgery. Le Fort I osteotomy. Facial profile. Lip profile.
\end{abstract}

\section{REFERÊNCIAS}

1. ARAÚJO, A. SCHENDEL, S. A. WOLFORD, L. M. EPKER, B. N. Total maxillary advancement with and without bone grafting. J Oral Surg, Chicago, v.36, p. 849-858, 1978.

2. AUGER, T. A.; TURLEY, P. K. Esthetic soft-tissue profile changes during the 1900s. J Dent Res, Chicago, v. 73, p. 21-28, 1994. IADR Abstracts

3. BAILEY, L. J.; COLLIE, F. M.; WHITE, J. R. Long-term soft tissue changes after orthognathic surgery. Int $\mathbf{J}$ adult Orthodon Orthognath Surg, Carol Stream, v.11, p. 7-18, 1996.

4. BELL, W. H. Revascularization and bone healing after anterior maxillary osteotomy: a study using adult rhesus monkeys. J Oral Surg, Chicago, v. 27, p. 249-255, 1969.

5. BELL, W. H. Le Fort I osteotomy for correction of maxillary deformities. J Oral Surg, Chicago, v. 33, p. 4-12, 1975

6. BELL, W. H.; ALESSANDRA, P. A.; CONDIT, C. L. Surgicalorthodontic correction of Class II malocclusion. J Oral Surg Chicago, v.26, p.265-272, 1968.

7. BELL, W. H.; DANN III, J. J. Correction of dentofacial deformities by surgery in the anterior part of the jaws. A stydy of stability and soft-tissue changes. Am J Orthod, St. Louis, v. 64, p. 162-187, 1973.

8. BELL, W. H.; SCHEIDEMAN, G. B. Correlation of vertical maxillary deficiency: stability and soft tissue changes. J Oral Surg, Chicago, v. 39, p. 666-670, 1981

9. BISHARA, S. E.; CUMMINS, D. M.; JAKOBSEN, J. R. The morphological basis for the extraction decision in Class II Division 1 malocclusions: a comparative study. Am J Orthod Dentofacial Orthop, St. Louis, v.107, p.129-135, 1995.
10. BISHARA, S. E.; CUMMINS, D. M.; JAKOBSON, J. R. ZAHER, A. R. Dentofacial and soft tissue changes in Class II Division 1 cases treated with and without extractions. Am J Orthod Dentofacial Orthop, St. Louis, v.107, p. 2837, 1995

11. BRAVO, L. A. Soft tissue facial profile changes after orthodontic treatment with four premolars extracted. Angle Orthod Appleton, v.64, p.31-41, 1994.

12. BUNDGAARD, M.; MELSEN, B.; TERP, S. Changes during and following total maxillary osteotomy (Le Fort I procedure): a cephalometrics study. Eur J Orthod, London, v. 8, p. 21-29, 1986.

13. CARLOTTI, A. E.; ASCHAFFENBURG, P. H.; SCHENDEL, S. A Facial changes associated with surgical advancement of the lip and maxilla. J Oral Maxillofac Surg, Philadelphia, v. 44, p. 593-596, 1986.

14. COHN-STOCK, G. Die chirurgische Immediategulierung der Kiefer, speziell die chrurgische Behandlung der Prognathie, Vjschr Zahnheilkd, [S. I.], v. 37, p.3-20, 1921

15. CUMMINS, D. M.; BISHARA, S. E.; JAKOBSEN, J. R. A computer assisted photogrammetric analysis of soft tissue changes after orthodontic treatment. Part II: results. Am J Orthod Dentofacial Orthop, St. Louis, v.108, p.38-47, 1995

16. DAHLBERG, G. Statistical methods for medical and biological students. London: George Allen and Unwin, 1940.

17. DANN, J. J.; FONSECA, R. J.; BELL, W. H. Soft tissue changes associated with total maxillary advancements: a preliminary study. J Oral Surg, Chicago, v. 34, p.19-23, 1976. 
18. EALES, E. A.; JONES, M. L.; NEWTON, C. SUGAR, A. W. A study of the accuracy of predicted soft tissue changes produced by a computer software package (COG 3.4) in a series of patients treated by the Le Fort I osteotomy. $\mathbf{B r} \mathbf{J}$ Oral Maxillofac Surg, London, v. 33, p. 362-369, 1995.

19. ENGEL, G. A.; QUAN, R. E.; CHACONAS, S. J. Soft tissue changes as result of maxillary surgery. A preliminary study. Am J Orthod, St. Louis, v. 75, p. 291-300, 1979.

20. FREIHOFER, H. P. M. The lip profile after correction of retromaxillism in cleft and non-cleft patients. J Maxillofac Surg, Philadelphia, v. 4, p.136-141, 1976.

21. KASAI, K. Soft tissue adaptability to hard tissues in facial profiles. Am J Orthod Dentofacial Orthop, St. Louis, v.113, p. 674-684, 1998.

22. KING, E.W. Variations in profile change and their significance in timing treatment. Angle Orthod, Appleton, v. 30, p.141-153, 1960.

23. KONSTIANTOS, K. A.; O'REILLY, M.T.; CLOSE, J. The validity of the prediction of soft tissue profile changes after Le Fort I osteotomy using the dentofacial planner (computer software). Am J Orthod Dentofacial Orthop, St. Louis, v. 105, p. 241-249, 1994.

24. LEE, D.Y.; BAILEY, L. J.; PROFFIT, W. R. Soft tissue changes after superior repositioning of the maxilla with Le Fort I osteotomy: 5-year follow-up. Int J Adult Orthodon Orthognath Surg, Carol Stream, v. 11, p. 301-311, 1996.

25. LINES, P. A.; STEINHAUSER, E.W. Soft-tissue changes in relation to movement of hard structures in orthognathic surgery: a preliminary report. J Oral Surg, Chicago, v. 32, p. 891-896, 1974.

26. MANSOUR, S.; BURSTONE, C.; LEGAN, H. An evaluation of soft tissue changes resulting from Le Fort I maxillary surgery. Am J Orthod, St. Louis, v. 84, p. 37-47, 1983.

27. MARTINS, D. R.; JANSON, G. R. P.; ALMEIDA, R. R.; PINZAN, A.; HENRIQUES, J. F. C.; FREITAS, M. R. Atlas de crescimento craniofacial. São Paulo: [s. n.], 1998.

28. NEGER, M. A quantitative method for the evaluation of the soft tissue facial profile. Am J Orthod, St. Louis, v. 45, p.738, 1959.
29. NGUYEN, D. D. TURLEY, P. K. Changes in the caucasian male facial profile as depicted in fashion magazines during the twentieth century. Am J Orthod Dentofacial Orthop, St. Louis, v. 114, p. 208-217, 1998.

30. OLIVER, B. M. The influence of lip thickness and strain on upper lip response to incisor retraction. Am J Orthod, St. Louis, v. 82, p.141-149, 1982.

31. RADNEY, L. J.; JACOBS, J. D. Soft tissue changes associated with surgical total maxillary intrusion. Am J Orthod, St. Louis, v. 80, p.191-212, 1981

32. ROSEN, H. M. Lip-nasal aesthetics following Le Fort I osteotomy. Plast Reconstr Surg, Baltimore, v. 81, p.171-182, 1988

33. RUDEE, D. A. Proportional profile changes concurrent with orthodontic therapy. Am J Orthod, St. Louis, v. 50, p. 421-434, 1964.

34. SAMESHIMA, G.T.; KAWAKAMI, R.K.; KAMINISHI, R. M.; SINCLAIR, P. M. Predicting soft tissue changes in maxillary impaction surgery: a comparison of two video imaging systems. Angle Orthod, Appleton, v. 67, p.347-354, 1997.

35. SCHENDEL, S. A.; EISENFELD, J. H.; BELL, W. H.; EPKER, B.N Superior repositioning of the maxilla: stability and soft-tissue osseous relations. Am J Orthod, St. Louis, v. 70, p. 663-674, 1976.

36. SCHUCHARDT, K. Experiences with the surgical treatment of some deformities of the jaws: prognathia, micrognathia, and open bite. In: WALLACE, A. B (Ed.). Transactions of second congress. London: International Society of Plastic Surgeons, 1961.

37. SHELlY, A. D.; SOUTHARD, T. E.; SOUTHARD, K. A.; CASKO, J. S.; JACOBSEN, J. R.; FRIDRICH, K. L.; MERGEN, J. L. Evaluation of profile esthetic change with mandibular advancement surgery. Am J Orthod Dentofacial Orthop, St. Louis, v. 117, p. 630-637, 2000

38. WASSMUND, J. Lehrbuch der praktischen Chirurgie des Mundes und der Kiefer. Leipzig: Herma Meusser, 1935. v. 1.

39. WISTH, P. J. Soft tissue response to upper incisor retraction in boys. Br J Orthod, London, v. 1, p.199-204, 1974.
Endereço para correspondência

Luciano Mauro Del Santo

Av. Vereador José Diniz 3.725, conj. 81

CEP: 04603-004 - Campo Belo - São Paulo - SP, Brasil.

luciano@neoface.com.br 